\title{
EPIDEMIOLOGY OF ENDEMIC OROPOUCHE VIRUS TRANSMISSION IN UPPER
} AMAZONIAN PERU

\author{
KATHY J. BAISLEY, DOUGLAS M. WATTS, LEONARD E. MUNSTERMANN, AND MARK L. WILSON \\ Department of Epidemiology and Public Health, Yale University School of Medicine, New Haven, Connecticut; U.S. Naval \\ Medical Research Institute Detachment, Lima, Peru; Department of Epidemiology, School of Public Health, \\ The University of Michigan, Ann Arbor, Michigan
}

\begin{abstract}
A cross-sectional serosurvey of a rural community near Iquitos, Peru was conducted to determine Oropouche (ORO) virus antibody prevalence and risk factors for human infection. Venous blood samples, and demographic, social, and risk factor data were obtained from people age five years of age and older who lived in the village of Santa Clara on the Nanay River, a tributary of the Amazon River. Sera were tested for ORO viral antibody by an ELISA. The specificity of viral antibody reactivity was determined by a standard plaque-reduction neutralization test. Interview data were analyzed by univariate and multiple logistic regression to determine which variables were statistically associated with previous ORO viral infection, as indicated by the presence of IgG antibody. Final models were evaluated based on log-likelihood and Wald chi-square. Clustering of seropositive residents within houses was analyzed by the method of Walter. Among 1,227 persons sampled, 33.7\% $(\mathrm{n}=414)$ were positive for ORO viral IgG antibody. Overall, antibody prevalence was similar for males (33.9\%) and females (33.6\%), and increased significantly with age for both sexes to include more than half of persons more than 25 years of age. The length of residence in the village was positively associated with serologic status; persons who had moved to the village within the past 15 years were less likely to be seropositive than life-long residents of the same age. Antibody prevalence among immigrants who had lived in Santa Clara more than 15 years was similar to that in life-long residents. The activity most predictive of previous ORO viral infection was travel to forest communities and travel to Iquitos. No evidence of spatial heterogeneity in ORO virus antibody distribution was observed. Results suggested that endemic transmission of ORO virus in this region has been ongoing during many decades, and that people are at considerable risk of infection.
\end{abstract}

Oropouche fever has emerged over the past 30 years as a serious public health problem in tropical South America. ${ }^{1-3}$ The virus was first isolated during 1955 in Trinidad from the blood of a febrile forest worker. ${ }^{4}$ The earliest documented epidemic of Oropouche fever occurred in 1961 in Belem, Para State, Brazil, and infected more than 11,000 people. ${ }^{1}$ Subsequently, at least 27 outbreaks have been recognized, the largest of which involved an estimated 102,000 people in $1980 .{ }^{3}$ For several decades, these outbreaks were confined to the Amazon Region of Brazil; however, the documented range of the virus expanded when cases were diagnosed during 1989 in Panama in 1989 and 1992 in Peru. ${ }^{3}$

Clinical features of Oropouche fever include abrupt onset of fever, chills, severe headache, dizziness, myalgia, arthralgia, nausea, and vomiting. Occasionally, neurologic involvement has been reported. ${ }^{2}$ The acute phase of illness usually ranges from two to seven days; however, a significant percentage of people may develop a recurrence of symptoms within 2-10 days after they become afebrile. All ages and both sexes appear to be equally susceptible to infection. A distinguishing characteristic of Oropouche (ORO) virus is the exceptionally high infection rate during outbreaks, with incidence exceeding $40 \%$ in some Brazilian epidemics. ${ }^{1,5}$ Clinical illness has been estimated to occur in approximately $60 \%$ of those infected. ${ }^{2}$

Transmission of ORO virus may involve two distinct cycles: an epidemic urban cycle with humans as the primary vertebrate host and a silent jungle cycle. The epidemic vector of ORO virus is thought to be the biting midge Culicoides paraensis (Goeldi). In the sylvatic cycle, primates, sloths, and birds have been proposed as vertebrate reservoirs, but the arthropod vector has not been identified. However, conclusive evidence of a jungle cycle is lacking, despite extensive investigations. ${ }^{1-3}$ Serologic studies during outbreaks have shown the rate of virus activity differed markedly within some urban centers. ${ }^{1,5,6}$ Presumably, spatial variations in virus transmission rates are related to microhabitats that favor high vector abundance.

The epidemiology and geographic distribution of Oropouche fever in Peru is largely unknown. The first isolation of ORO virus in Peru occurred in 1992 during investigations of dengue fever in Iquitos, a port city on the Amazon river. ${ }^{5}$ Except for data generated by a retrospective cross-sectional serosurvey in Peru, ${ }^{7}$ knowledge of transmission and risk factors is based largely on observations made during epidemics in Brazil. ${ }^{1,2,5,6,8}$ Little is known about endemic transmission and the ecology of enzootic maintenance cycles of the virus. Furthermore, no systematic analysis of potential risk factors for human infection has yet been reported. Accordingly, a cross-sectional serologic survey of a rural community was conducted near Iquitos to determine community-wide prevalence of ORO virus antibody, risk factors for human infection, the spatial distribution of previous exposure, and possible environmental correlates of risk.

\section{MATERIALS AND METHODS}

Study site and population. The study was conducted in Santa Clara, a village of 2,409 residents located in the Amazon River basin, $10 \mathrm{~km}$ southwest of Iquitos in the Department of Loreto, Peru. The total population of Santa Clara was estimated by a census conducted by the village health clinic during the study period. Iquitos, a city with approximately 300,000 inhabitants, is located 120 meters above sea level at latitude $3^{\circ} 40^{\prime} \mathrm{S}$ and longitude $73^{\circ} 10^{\prime} \mathrm{W}$. Santa Clara is situated along the Nanay River, a tributary of the Amazon, and occupies an area of approximately $6 \mathrm{~km}^{2}$. Village residents were mostly of mixed Spanish and American Indian 
ancestry. Occupations were predominantly in agriculture and fishing, although approximately $6 \%$ of the residents worked as wage laborers in Iquitos. The village did not have electricity or piped water service. Houses were built primarily of wood or concrete block, with palm leaf or corrugated aluminum roofs. Most residences had a small plot of land, and fruit trees were often cultivated. Surrounding vegetation was primarily cultivated land, abandoned cropland that had been densely overgrown, or secondary forest. The climate is tropical, with an average temperature of $27.5^{\circ} \mathrm{C}$ and a mean annual precipitation of 2.7 meters.

Study cohort. All Santa Clara residents five years of age and older were eligible to participate in the study. Participants were enrolled during a visit to their homes. Written consent was obtained from each participant, or from a parent or guardian when the person was less than 18 years old. The study protocol was reviewed and approved by the Naval Medical Research Institute Committee for the Protection of Human Subjects and by the Yale University School of Medicine Human Investigation Committee.

Blood samples and analysis. A venous blood sample was collected from each study participant using a needle and evacuated tube. A 5-ml sample was drawn from children less than 15 years of age, and a 7-ml sample was obtained from older participants. Samples were collected during June-September 1996, by going house-to-house during daily visits to the village. At the end of each day, samples were returned to the laboratory, centrifuged, and the serum fraction was transferred to sterile one-dram vials. These were stored at $-20^{\circ} \mathrm{C}$ until tested for ORO viral IgG antibody.

Questionnaire. Demographic, social, and risk factor data were obtained by administering a standardized questionnaire. All participants were interviewed at their homes in Spanish by the same interviewer. Parents were asked to answer for children less than 10 years of age. The interview provided information on age, gender, number of people in the household, and medical history related to the occurrence of febrile illnesses in the past six months. In addition, questions were asked regarding frequency of travel to the forest, river, the city of Iquitos, and other rural villages. House construction and distance to banana or cacao trees were recorded.

Serologic assays. Sera were tested for ORO viral IgG using an ELISA. ${ }^{7}$ The ORO virus-infected and -uninfected Vero cell culture lysates were coated directly onto 96-well, flat-bottomed microtiter plates. Sera were diluted 1:100 in phosphate-buffered saline (PBS) supplemented with 5\% nonfat dried milk, $0.1 \%$ Tween-20, and $0.0001 \%$ thimerosal. Aliquots were added to each of two ORO virus antigencoated wells, and two uninfected cell lysate-coated control wells (mock antigen). The ORO virus IgG antibody-positive and negative human sera were tested as controls in each assay. Wells were washed repeatedly with the serum-dilution diluent, followed by a 1-hr incubation at room temperature. Afterwards, horseradish peroxidase-conjugated mouse antihuman IgG ( $\mu$-chain specific) was added to each well to detect the presence of bound ORO virus IgG antibody. The wells were washed as before, and an enzyme substrate, ABTS (2,2'-azino di-3-ethyl benzthiazoline sulfonate), was added and allowed to incubate for $1 \mathrm{hr}$ at room temperature. The optical density (OD) value of each microtiter plate well was read by a microplate spectrophotometer at a wavelength of $414 \mathrm{~nm}$. Corrected absorbance values were obtained by subtracting the OD values for the mock antigen wells from those of the wells with ORO viral antigen. Sera dilutions with corrected absorbance values greater than the reference cut-off value, estimated as the mean absorbance of 10 antibody-negative sera plus three standard deviations, were considered antibody-positive.

Confirmation of antibody identity. The specificity of antibody reactivity was determined by a standard plaque-reduction neutralization test (PRNT). ${ }^{7}$ All sera that were considered antibody positive by the ELISA were diluted 1:10 in Eagle's minimum essential medium (EMEM) supplemented with $2 \%$ fetal calf serum heat-treated at $56^{\circ} \mathrm{C}$ for $30 \mathrm{~min}$. After incubating each dilution with approximately 50 plaque-forming units (PFUs) of ORO virus, aliquots of the mixture were inoculated onto confluent monolayers of Vero cell cultures propagated in $25-\mathrm{cm}^{3}$ flasks. Cells and inoculum were incubated at $37^{\circ} \mathrm{C}$ for $1 \mathrm{hr}$ and then overlayed with Seakem agarose-EMEM (Quality Biological, Inc., Gaithersburg, MD) supplemented with $5 \%$ fetal bovine serum, penicillin (200 units/ml), and streptomycin $(200 \mu \mathrm{g} / \mathrm{ml})$. Cells were overlayed with a 5\% neutral red-EMEM agarose on days 4 or 5 postinoculation to enumerate PFUs. Cultures that received the viral dose plus a 1:10 dilution of ORO viruspositive and -negative human sera were included. Sera that reduced the viral PFU dose by $70 \%$ or greater were considered positive for ORO antibody.

Statistical analysis. Questionnaire data were analyzed to determine which variables were statistically associated with previous ORO virus infection, as indicated by the presence of IgG antibody. Univariate analysis (Pearson's chi-square and logistic regression) and multiple logistic regression were performed using SAS for Windows, Version 6.1 (SAS Institute, Inc., Cary, NC). Combinations of all significant marginal associations $(P<0.05)$ from the univariate analyses were entered into multiple logistic regression models. Final models were evaluated based on log-likelihood and Wald chi-square. Clustering of seropositive residents within houses was analyzed by the method of Walter, which tested for the frequency of pairing of seropositive individuals within households. ${ }^{9}$

\section{RESULTS}

Population sampled. An estimated total of 2,000 Santa Clara residents met the age requirements for entry into the study. Of these, 1,230 (61.5\%) agreed to participate. Adequate blood samples were not obtained from three persons; the remaining 1,227 residents were included in the study (551 males and 676 females). Household enrollment was $78.4 \%$, or 320 of 408 houses. Sera were collected from all eligible members in 137 of these households. In the remaining 183 houses, samples were obtained from approximately $62 \%$ of eligible members. Study subjects ranged in age from five years to more than 70 years old; the average age was 26.7 years for males and 24.8 years for females. Participants were mostly farmers and fishermen (16\%), housewives (28\%), and students (38\%). A total of $58 \%$ of the sampled population had lived in Santa Clara their entire lives. Among those who had moved to Santa Clara, the average length of 
TABLE 1

Prevalence of Oropouche virus IgG antibody by age group among residents of Santa Clara village, Amazon River basin, Peru during June-September 1996

\begin{tabular}{lccc}
\hline & \multicolumn{3}{c}{ \% IgG positive (no. sampled) } \\
\cline { 2 - 4 } Age (years) & \multicolumn{1}{c}{ Total } & Males & Females \\
\hline $5-9$ & $5.5(272)$ & $4.9(122)$ & $6.0(150)$ \\
$10-14$ & $6.7(193)$ & $5.7(87)$ & $7.5(106)$ \\
$15-19$ & $12.1(107)$ & $8.1(37)$ & $14.3(70)$ \\
$20-24$ & $27.5(120)$ & $28.0(50)$ & $27.1(70)$ \\
$25-29$ & $54.7(106)$ & $51.2(43)$ & $57.1(63)$ \\
$30-34$ & $64.1(92)$ & $61.7(47)$ & $66.7(45)$ \\
$35-39$ & $59.5(79)$ & $52.8(36)$ & $65.1(43)$ \\
$40-44$ & $75.4(57)$ & $76.0(25)$ & $75.0(32)$ \\
$45-64$ & $69.6(148)$ & $72.6(73)$ & $66.7(75)$ \\
$\geq 65$ & $56.6(53)$ & $54.8(31)$ & $59.1(22)$ \\
Total & $33.7(1,227)$ & $33.9(551)$ & $33.6(676)$ \\
$P$ values for & & & \\
$\quad$ linear trend* & $<0.001$ & $<0.001$ & $<0.001$ \\
\hline * Unweighted logistic regression. & \multicolumn{4}{l}{}
\end{tabular}

residence was 10 years. One-third of them had moved to the village from Iquitos.

Antibody prevalence. A total of 414 (33.7\%) residents was positive for ORO virus ELISA IgG antibody. Antibody prevalence was similar for males $(33.9 \%)$ and females $(33.6 \%)$. Seroprevalence increased significantly with age for both sexes (Table 1). Persons more than 25 years old exhibited more than an nine-fold greater seroprevalence than those in the youngest age group. When separated into two age groups of $<25$ years and $\geq 25$ years, seroprevalence increased significantly in the younger age group $(P<0.001)$, but not among the older residents.

Antibody prevalence among persons who had moved to Santa Clara within the past 15 years was lower than that of life-long Santa Clara residents of the same age (Table 2). For example, seroprevalence averaged $71.1 \%$ in life-long residents 25 years of age and older, compared with $46.8 \%$ in persons of the same age who had lived in the village less than 15 years. Seroprevalence among immigrants who had lived in Santa Clara longer than 15 years was similar to that of lifelong residents $(75.2 \%)$.

Confirmation of the presence of ORO virus antibody. All of the 414 ELISA IgG antibody-positive sera were tested by PRNT for ORO viral antibody. Of these, 390 sera were positive and $24(5.8 \%)$ were negative by the PRNT. Even if these 24 samples were considered to be false-positive results, this would produce a minor decrease in the overall prevalence from $33.7 \%$ by the ELISA to $31.9 \%$ by the PRNT. Comparison of results based on ELISA versus PRNT antibody prevalences indicated no differences in the conclusions of our study.

Risk factors. Univariate analysis of the data indicated that many variables were significantly associated with the presence of ORO virus IgG antibody in the univariate analysis (Table 3). People who lived near the Nanay River were more likely to have ORO virus $\mathrm{IgG}$ antibody (odds ratio [OR] = $1.29, P<0.04)$ than those who lived in the village center or on the village outskirts. Travel history also predicted antibody status. Persons who reported regular travel (one or more trips/month) on the Nanay River or to forest communities were most likely to be seropositive (OR $=5.45, P<$
TABLE 2

Prevalence of Oropouche virus IgG antibody by age group among lifelong residents of Santa Clara, Peru and those who moved to the village from another location

\begin{tabular}{cccc}
\hline & \multicolumn{3}{c}{$\%$ seropositive (no. sampled) } \\
\cline { 2 - 4 } $\begin{array}{c}\text { Age } \\
\text { (years) }\end{array}$ & $\begin{array}{c}\text { Lifelong } \\
\text { residents }\end{array}$ & $\begin{array}{c}<15 \text { years } \\
\text { residence }\end{array}$ & $\begin{array}{c}\geq 15 \text { years } \\
\text { residence }\end{array}$ \\
\hline $5-14$ & $6.1(362)$ & $5.8(103)$ & $(0)$ \\
$15-24$ & $18.4(114)$ & $21.0(100)$ & $30.8(13)$ \\
$25-34$ & $69.5(95)$ & $43.4(83)$ & $75.0(20)$ \\
$35-44$ & $70.0(60)$ & $54.8(42)$ & $73.5(34)$ \\
$\geq 45$ & $74.0(77)$ & $45.9(61)$ & $76.2(63)$ \\
\hline
\end{tabular}

0.001). Those who reported regular travel to Iquitos were also more likely to be seropositive $(\mathrm{OR}=2.76, P<0.001)$ than participants who reported no travel. Frequency of river and forest travel was positively associated with seroprevalence $(\mathrm{OR}=1.06, P<0.001)$; however, frequency of travel to Iquitos was not predictive of antibody status $(P=0.114)$.

People whose occupational activities involved farming, fishing and housework were more likely to have ORO virus IgG antibody than people involved in other occupations (OR $=5.40, P<0.001)$. Place of occupation also was significant; persons who worked in forest or locations along the rivers were most likely to be seropositive ( $\mathrm{OR}=4.34, P<0.001)$. An increase in length of residence in Santa Clara was predictive of previous ORO virus infection $(\mathrm{OR}=1.06, P<$ 0.001). A febrile illness in the last six months was associated with seroprevalence $(\mathrm{OR}=1.79, P<0.001)$, as was a visit to a health provider $(\mathrm{OR}=1.59, P<0.003)$ and the number of reported malaria episodes $(\mathrm{OR}=1.26, P<0.01)$. People who lived in wood or brick houses built on the ground were more likely to be seropositive than those who lived in houses built on stilts $(\mathrm{OR}=1.90, P<0.02)$. The number of household members was negatively associated with seropositivity (OR $=0.95, P<0.03)$. Sex was not predictive of antibody status $(P=0.89)$, nor were most variables that concerned housing conditions (Table 4 ).

Because the univariate analyses did not evaluate possible confounding or correlation among risk factors, multivariate logistic regression models were used to test the significance of each variable factor while adjusting for the effects of other covariates. Combinations of all significant marginal associations from the univariate analyses were entered into multivariate logistic regression models. The only variables that remained predictive of ORO virus antibody prevalence in the adjusted models were age, place of travel, length of residence, and the number of reported malaria episodes (Table 5). These risk factors remained significant when we controlled for sex in the logistic model. No other combinations of covariates were statistically significant.

Spatial variation. To examine the spatial distribution of ORO virus antibody, seroprevalence among households was compared (Table 6). The 414 seropositive persons came from $243(75.9 \%)$ of the households sampled, and represented $81.7 \%$ of the study population. Households were grouped according to the observed frequency of seropositive individuals in each. This distribution was compared with that expected if seropositive residents were distributed at random. More houses were found with one or two seropositive 
TABLE 3

Reported activities or characteristics significantly associated with Oropouche virus IgG antibody among 1,227 residents of Santa Clara village, Amazon River basin, Peru

\begin{tabular}{|c|c|c|c|c|}
\hline \multicolumn{2}{|c|}{ Activity/characteristic } & \multirow{2}{*}{$\begin{array}{c}\begin{array}{c}\% \text { positive } \\
\text { (no. sampled) }\end{array} \\
36.1 \text { (993) }\end{array}$} & \multirow{2}{*}{$\frac{P^{*}}{<0.001}$} & \multirow{2}{*}{$\frac{\mathrm{OR}(95 \% \mathrm{CI}) \dagger}{1.79(1.29-2.48)}$} \\
\hline Febrile illness (past 6 months) & & & & \\
\hline Visit health provider & & $36.0(948)$ & 0.002 & $1.59(1.18-2.14)$ \\
\hline \multirow[t]{3}{*}{ Malaria episodes } & None & $17.2(186)$ & $<0.001$ & $1.26(1.19-1.34)$ \\
\hline & $1-2$ & $28.7(550)$ & & \\
\hline & $\geq 3$ & $45.2(482)$ & & \\
\hline \multirow[t]{3}{*}{ Residence (years) } & $<5$ & $23.2(224)$ & $<0.001$ & $1.06(1.05-1.07)$ \\
\hline & $5-14$ & $15.9(527)$ & & \\
\hline & $\geq 15$ & $58.4(476)$ & & \\
\hline \multirow[t]{2}{*}{ Lifelong resident } & No & $39.7(519)$ & $<0.001$ & $1.58(1.2-2.01)$ \\
\hline & Yes & $29.4(708)$ & & \\
\hline \multirow[t]{3}{*}{ No. of persons/house } & $1-3$ & $42.4(92)$ & 0.022 & $0.95(0.91-0.99)$ \\
\hline & $4-7$ & $34.8(653)$ & & \\
\hline & $\geq 8$ & $30.7(482)$ & & \\
\hline \multirow[t]{3}{*}{ Occupation } & Fishing/Agriculture & $56.2(194)$ & $<0.001$ & $5.86(4.15-8.27)$ \\
\hline & Housewife & $52.3(348)$ & $<0.001$ & $5.01(3.76-6.67)$ \\
\hline & Other $\ddagger$ & $18.0(685)$ & & 1.00 \\
\hline Location & Forest/river & $65.3(124)$ & $<0.001$ & $4.34(2.92-6.43)$ \\
\hline \multirow[t]{3}{*}{ House type } & Wood/on ground & $34.9(829)$ & 0.007 & $1.87(1.18-2.96)$ \\
\hline & Brick/concrete & $35.2(281)$ & 0.012 & $1.90(1.16-3.14)$ \\
\hline & Wood/on stilts & $19.4(98)$ & & 1.00 \\
\hline House location & Near river & $37.0(527)$ & 0.036 & $1.29(1.02-1.64)$ \\
\hline \multirow[t]{3}{*}{ Regular travel } & Iquitos & 30.7 (499) & $<0.001$ & $2.76(1.83-4.17)$ \\
\hline & Forest/river & 46.6 (489) & $<0.001$ & $5.45(3.63-8.20)$ \\
\hline & No travel & $12.9(233)$ & & 1.00 \\
\hline \multirow{4}{*}{$\begin{array}{l}\text { River/forest travel } \\
\text { (trips/week) }\end{array}$} & & & & \\
\hline & $<1$ & $33.7(101)$ & $<0.001$ & $1.06(1.03-1.08)$ \\
\hline & $1-2$ & 42.8 (138) & & \\
\hline & $\geq 3$ & $61.1(203)$ & & \\
\hline
\end{tabular}

* For continuous variables, $P$ and odds ratios (ORs) are reported from logistic regression analysis of variables as continuous data. For categorical variables with $>$ two levels, ORs and $P$ reflect comparison of each category with the last listed category (reference).

$\dagger \mathrm{CI}=$ confidence interval.

$\ddagger$ The majority were students (463); includes tradespeople, craftsmen, business merchants, teachers, and health workers.

members and fewer with zero or three seropositive members $(P<0.04)$.

Observed and expected frequencies of pairings of seropositive individuals within a household were calculated according to the method of Walter. ${ }^{9}$ A random distribution of the 414 seropositive persons among the 1,227 inhabitants of the 320 households would result in chance pairings within a household on 263 occasions, as opposed to the 241 pairings observed in this study $(P>0.07)$. Consequently, no clear evidence for clustering of infections within households was apparent.

\section{DISCUSSION}

This study is the first in Peru to examine the prevalence of ORO virus antibody on a community-wide basis, and is one of few systematic investigations of risk factors for human infection. Most previous reports on the epidemiology of Oropouche fever have described characteristics of infected communities in Brazil during or shortly after outbreaks. ${ }^{6,79}$ Only one other serosurvey in the Peruvian Amazon has been published; that study of five communities in the Iquitos area described antibody prevalence in small, varied subsamples of the populations.?

Since the ELISA does not distinguish ORO viral IgG antibody from those induced by other members of the Simbu serogroup viruses, ${ }^{10}$ all reactive sera were tested by the PRNT. As a commonly used test to determine the specificity of arboviral IgG antibodies, the PRNT results indicated that 94\% (390 of 414) of the ELISA antibody-positive sera were also positive by the PRNT, thus verifying that most antibody reflected ORO viral infection. Although there was a discrepancy in results between the two assays, the difference was so minor that either results yielded the same conclusions.

Our study evaluated risk factors for past ORO virus infection among the majority of residents of Santa Clara, a rural community near Iquitos. Unlike other such studies, which generally sampled less than $15 \%$ of a village, nearly $80 \%$ of the households and $61 \%$ of the residents five years of age and older participated in our study. More than onethird of Santa Clara residents had evidence of past infection with ORO virus. Seroprevalence increased significantly with age for both sexes to nearly two-thirds of persons 60 years of age and older. These findings were consistent with those from the previous Iquitos-area survey in which the average seroprevalence was $28 \%$, with more than $70 \%$ of the persons 60 years of age and older having antibodies. ${ }^{7}$

In areas of Brazil where ORO virus appears to be endemic but that lack recognized epidemic transmission, antibody prevalences ranging from $0 \%$ to $2 \%$ have been reported. ${ }^{1}$ In contrast, surveys in Brazil undertaken after outbreaks of Oropouche fever showed that antibody prevalences ranged from $17 \%$ to $44 \% .^{2,5,6,8}$ Although recent outbreaks have not been recognized in Santa Clara, the high prevalence of antibody in this population suggests hyperendemic or past epidemic transmission of ORO virus in the region. 
TABLE 4

Reported activities or characteristics unassociated with Oropouche virus antibody among residents of Santa Clara village, Peru

\begin{tabular}{|c|c|c|c|c|}
\hline \multicolumn{2}{|c|}{ Activity/characteristic } & \multirow{2}{*}{$\begin{array}{c}\begin{array}{c}\% \text { positive } \\
\text { (no. sampled) }\end{array} \\
35.0(240)\end{array}$} & \multirow{2}{*}{$\frac{P}{0.65}$} & \multirow{2}{*}{$\frac{\mathrm{OR}(95 \% \mathrm{CI})}{1.07(0.79-1.46)}$} \\
\hline Length of febrile illness (days) & $1-3$ & & & \\
\hline \multirow{2}{*}{ Sex } & Male & $33.9(551)$ & 0.89 & $1.02(0.80-1.29)$ \\
\hline & Female & $33.6(676)$ & & \\
\hline \multirow{2}{*}{ Water source } & Well & $33.5(925)$ & 0.71 & $0.99(0.92-1.06)$ \\
\hline & River & 34.7 (302) & & \\
\hline \multirow{2}{*}{ Place of occupation } & Iquitos & $29.5(78)$ & 0.88 & $0.96(0.58-1.59)$ \\
\hline & Santa Clara & 30.3 (997) & & \\
\hline \multirow[t]{2}{*}{ Roof construction } & Thatch & $33.1(738)$ & 0.46 & $1.10(0.86-1.40)$ \\
\hline & Metal & $35.1(486)$ & & \\
\hline \multirow[t]{2}{*}{ House location } & Center & $33.0(522)$ & 0.10 & $1.37(0.94-2.00)$ \\
\hline & Outskirts & $25.6(172)$ & & \\
\hline Banana/cacao present & Yes & $34.0(1,166)$ & 0.53 & $1.20(0.68-2.11)$ \\
\hline \multirow[t]{3}{*}{ Distance to banana/cacao (m) } & $<10$ & $33.1(792)$ & 0.12 & $1.15(0.96-1.37)$ \\
\hline & $10-20$ & $32.0(247)$ & & \\
\hline & $\geq 21$ & $42.6(122)$ & & \\
\hline \multirow[t]{2}{*}{ Sanitary facilities } & Latrine & $34.3(496)$ & 0.42 & $2.20(0.87-1.40)$ \\
\hline & None & $33.6(651)$ & & \\
\hline \multirow{3}{*}{ Travel to Iquitos (trips/week) } & $<1$ & $34.8(287)$ & 0.11 & $1.02(1.00-1.04)$ \\
\hline & $1-2$ & $38.5(278)$ & & \\
\hline & $\geq 3$ & $41.6(308)$ & & \\
\hline
\end{tabular}

Two distinct cycles of transmission have been proposed: an urban epidemic cycle in which humans are the primary host, and a silent maintenance cycle in which forest animals are the vertebrate hosts and humans are normally not involved. ${ }^{1,2}$ Although isolated human cases may occur from sylvatic spillover, most human infection is thought to take place during urban outbreaks of Oropouche fever. Alternatively, ORO virus may circulate continuously in villages at low levels that are not recognized epidemics. ${ }^{3,7}$ This alternative model of virus maintenance appears consistent with the age-sex distribution of ORO antibody prevalence observed in Santa Clara. Although overall seroprevalence was high, it was markedly lower among persons in the younger age groups. In residents less than 25 years of age, antibody prevalence increased slowly from $5.5 \%$ in the youngest group to a maximum of $26.7 \%$ in persons $20-25$ years of age. These prevalence rates are substantially lower than those reported in similar age groups after epidemics of Oropouche fever. ${ }^{1}$ Cross-sectional studies in Santarem, Brazil found that $22 \%$ of persons less than 10 years of age had IgG antibody following an Oropouche fever outbreak. ${ }^{6}$ After the first isolation of ORO virus during 1992 in Iquitos, Watts and others ${ }^{7}$ reported an incidence of $18 \%$ in the $0-9$-yearold age group and $29 \%$ in the 10-19-year-old age group in

TABLE 5

Significant independent associations between reported characteristics and Oropouche virus IgG antibody prevalence by multiple logistic regression analysis

\begin{tabular}{lcc}
\hline \multicolumn{1}{c}{ Activity or characteristic } & $P^{*}$ & Adjusted OR $(95 \% \mathrm{CI}) \dagger$ \\
\hline Age & 0.0001 & $1.05(1.04-1.06)$ \\
Length of residence & 0.0001 & $1.02(1.01-1.04)$ \\
Travel to Iquitos & 0.0002 & $2.62(1.58-4.34)$ \\
Forest/river travel & 0.0001 & $3.19(1.92-5.28)$ \\
Number malaria episodes & 0.0004 & $1.12(1.05-1.20)$ \\
\hline
\end{tabular}

$* P$ values from logistic regression of Oropouche virus antibody as a function of all five covariates.

$\dagger \mathrm{OR}=$ odds ratio; $\mathrm{CI}=$ confidence interval.
Primavera, a rural community located adjacent to Iquitos. Lower seroprevalence in Santa Clara residents less than 25 years of age and a gradual increase in seropositivity with age suggested that ORO virus infection in this younger group may be primarily the result of sustained low-level endemic transmission.

The previous study of communities near Iquitos estimated the annual incidence of endemic ORO virus infection at 12 cases per 100 susceptible population. ${ }^{5}$ This calculation is consistent with the age group-specific prevalences for persons less than 25 years of age determined in our study. However, residents 25 years of age and older had a seroprevalence higher than would be expected if this level of annual incidence had been consistent. This gradual increase in agespecific antibody prevalence increased dramatically to $55 \%$ among 25-29-year-old individuals, and even higher in older persons. Such a marked increase in antibody prevalence among Santa Clara resident more than 25 years of age may be a result of past epidemic transmission, previously elevated levels of endemic transmission, or additional exposures that augment risk of infection in older age groups. Because seroprevalence did not continue to increase into the oldest age groups, some detectable antibodies may be lost with age.

The difference in seroprevalence between life-long and non-native Santa Clara residents also suggests a past outbreak or previously higher levels of endemic transmission of ORO virus. Seroprevalence was significantly lower among more recent immigrants than among life-long residents of the same age. Antibody prevalence was not significantly different between life-long residents and non-natives who had lived in Santa Clara more than 15 years. Perhaps recent immigrants engaged in different activities than native or longterm residents, and thereby placed themselves at lower risk of infection. However, this seems less likely than the possibility of epidemic or elevated transmission.

The activity most predictive of past infection was travel to forest communities or river travel, an association that was 
TABLE 6

Lack of evidence of clustering of Oropouche virus IgG antibody among 1,227 persons in 320 houses in Santa Clara village, Amazon River basin, Peru

\begin{tabular}{cccr}
\hline No. of cases per household & No. of cases observed & No. of cases expected* & Observed-expected $\dagger$ \\
\hline 0 & 77 & 88.4 & -11.4 \\
1 & 127 & 116.3 & 10.7 \\
2 & 84 & 71.3 & 12.7 \\
3 & 19 & 30.4 & -11.4 \\
4 & 12 & & -1.5 \\
SD Walter ${ }^{9}$ test for aggregation in households & & 414 \\
No. of positive individuals & & 243 \\
No. of households with positive individuals & & 241 \\
Observed frequency of pairing of individuals in households & & 263.56 \\
Expected frequency of pairing of individuals in households & & $P>0.07$ \\
Result: no clustering within compounds $(\mathrm{z}=-1.41)$ & & \\
\hline
\end{tabular}

* Based on binomial probability distribution.

$\dagger$ Chi-square $=8.98$, three degrees of freedom, $P<0.04$

significant for both sexes. Visits to forest villages often occur for purposes of crop cultivation; many Santa Clara residents farm small plots of land along the Nanay River. Our findings are consistent with those from other communities in the region around Iquitos in which ORO virus seroprevalence was highest $(46 \%)$ in a forest village. ${ }^{7}$ The association of increased infection with place of travel may be related to an increased exposure to the suspected vector midge Culicoides paraensis. Studies in Brazil have suggested that agricultural practices related to the growing of banana and cacao lead to the creation of larval habitat for this insect. ${ }^{711-13}$ However, C. paraensis is also found in forests where it may oviposit in tree-hole debris. ${ }^{14}$ Furthermore, forest or river travel may bring people into contact with a sylvatic transmission cycle of ORO virus. Midge abundance has yet to be compared between forested slash-and-burn, agricultural sites, and more extensively cleared villages such as Santa Clara. Entomologic studies are needed to determine not only the distribution and density of Culicoides spp., but also other potential arthropod vectors in this area.

Travel to the city of Iquitos also was found to be independently associated with antibody prevalence in the multivariate model. The reasons for this association are unclear. Perhaps Iquitos residents experience sporadic epidemic transmission of ORO virus similar to that reported from urban centers in the Brazilian Amazon. A 1994 cohort study of Iquitos school children showed annual incidence rates of $21 \%$ in some parts of the city (Watts DM and others, unpublished data). Another investigation of a 1992 dengue outbreak in Iquitos also revealed cases of ORO virus infection, although incidence rates were not reported. ${ }^{3}$ Santa Clara residents who visited Iquitos might have come into contact with urban epidemic transmission of the virus, placing them at a higher risk of infection than normally encountered in the village. Alternatively, travel to Iquitos might represent a marker for some other behavior or exposure that represents the true risk of virus infection.

The correlation of malaria episodes with ORO virus antibody prevalence was puzzling. Santa Clara has a small health clinic, and malaria smears and treatment are offered free of charge. However, the proportion of clinically diagnosed malaria episodes that were reported in our interview is uncertain. The vectors and transmission cycles of ORO virus and Plasmodium are different, probably with differing risk factors for human infection. The association between number of malaria episodes and ORO virus antibody may reflect increased outdoor activity, general exposure to arthropod vectors, or unrecognized ecological variables associated with household location.

The comprehensive nature of the present survey allowed us to examine the spatial distribution of ORO virus antibody in Santa Clara. Previous epidemiologic studies of ORO virus suggested that transmission may be spatially heterogeneous. ${ }^{1,2}$ For example, after Oropouche fever outbreaks in Belem and Santarem, Brazil, the distribution of virus activity was noted to be markedly uneven. ${ }^{1,6}$ However, no spatial patterns indicating focal infection within households or neighborhoods in Santa Clara were observed in this study. No clustering of seropositive residents within households was apparent, like what would be expected if virus transmission had been unevenly distributed in the village. Belem and Santarem are large urban centers with populations of more than 100,000 . Spatial heterogeneity in large cities may be related to socioeconomic factors associated with the occurrence of Culicoides larval habitat in certain neighborhoods. In contrast, smaller communities such as Santa Clara are probably more homogeneous with respect to larval midge habitat; significant differences in virus transmission, if present, are difficult to detect. Apparently, environmental risk factors around houses were similar, or infection occurred primarily away from people's residences.

While significant in the univariate analysis, house location was not associated with ORO virus antibody in the final multivariate analysis. House location was categorized broadly into three groups: near the river, in the village center, or along the dirt road leading out of town. Two significant risk factors, place of travel and length of residence, also were associated with house location. People who lived near the river were more likely to travel to the forest, while people who lived on the outskirts of town reported the least travel. In addition, people who lived on the outskirts of town were more likely to be recent residents. These factors may have obscured relationships between house location and ORO virus antibody status.

Although the presence or proximity of banana/cacao plants to houses has often been reported as a potential risk factor for ORO virus infection, $, 2,3,8,12$ we found no association between this and seroprevalence. At least $68 \%$ of houses in 
Santa Clara had banana or cacao plants $<10$ meters from the residence. Some houses were associated with isolated stands of young plants, some had dense growth of mature plants, others were located near rows of commercially grown plants. The simple presence/absence variable probably did not assess adequately the variations in habitat that might favor elevated vector abundance. Studies are needed to examine the distribution and density of Culicoides populations in relationship to household seroprevalence. Additional analyses of the spatial distribution of human infection in relation to ecologic features will allow better understanding of determinants of ORO virus transmission, and may help control the threat that Oropouche fever poses to human health in this region.

Acknowledgments: We thank Carolina Guevara, Vidal Felices Aedo, and members of the U.S. Naval Medical Research Institute Detachment Virology Laboratory in Lima, and Karla Block, Dr. Jeny Cordova Rios, and Zoila Reategui in Iquitos for technical help and advice.

Financial support: This work was supported in part by grants from the Downs International Travel Fellowship at Yale University to Kathy J. Baisley, and from the National Institute of Allergy and Infectious Diseases to Leonard E. Munstermann (AI-34521) and Mark L. Wilson (AI-34409).

Authors' addresses: Kathy J. Baisley, Department of Biology, Mahidol University, Bangkok, Thailand. Douglas M. Watts, U.S. Naval Medical Research Institute Detachment, Lima, Peru. Leonard E. Munstermann, Department of Epidemiology and Public Health, Yale University School of Medicine, New Haven, CT 06520-8034. Mark L. Wilson, Department of Epidemiology, School of Public Health, The University of Michigan, 109 Observatory Street, Ann Arbor, MI 48109-2029.

Reprint requests: Mark L. Wilson, Department of Epidemiology, School of Public Health, The University of Michigan, 109 Observatory Street, Ann Arbor, MI 48109-2029.
REFERENCES

1. Pinheiro FP, Travassos da Rosa AP, Travassos da Rosa JF, Ishak R, Freitas RB, Gomes ML, LeDuc JW, Oliva OF, 1981. Oropouche virus: a review of clinical, epidemiological, and ecological findings. Am J Trop Med Hyg 30: 149-160.

2. LeDuc JW, Pinheiro FP, 1988. Oropouche fever. Monath TP, ed. The Arboviruses: Epidemiology and Ecology. Volume IV. Boca Raton FL: CRC Press, 1-15.

3. Tesh RB, 1994. The emerging epidemiology of Venezuelan hemorrhagic fever and Oropouche fever in tropical South America. Ann NY Acad Sci 740: 129-137.

4. Anderson CR, Spence L, Downs WG, Aitken TH, 1961. Oropouche virus: a new human agent from Trinidad, West Indies. Am J Trop Med Hyg 10: 574-578.

5. Dixon KE, Travassos da Rosa AP, Travassos da Rosa JF, Llewellyn CH, 1981. Oropouche virus: epidemiological observations during an epidemic in Santarem, Para, Brazil in 1975. Am J Trop Med Hyg 30: 161-164.

6. LeDuc JW, Hoch AL, Pinheiro FP, Travassos da Rosa AP, 1981. Epidemic Oropouche virus in northern Brazil. Bull Pan Am Health Organ 15: 97-103.

7. Watts DM, Phillips I, Callahan JD, Griebenow W, Hyams KC, Hayes CG, 1997. Oropouche virus transmission in the Amazon river basin of Peru. Am J Trop Med Hyg 56: 148-152.

8. Roberts DR, Hoch AL, Dixon KE, Llewellyn CH, 1981. Oropouche virus: entomological observations from three epidemics in Para, Brazil, 1975. Am J Trop Med Hyg 30: 165-171.

9. Walter SD, 1974. On the detection of household aggregation of disease. Biometrics 30: 525-538.

10. Kinney RM, Calisher CH, 1981. Antigenic relationships among simbu serogroup (Bunyaviridae) viruses. Am J Trop Med Hyg 30: $1307-1318$

11. Linley JR, Hoch AL, Pinheiro FP, 1983. Biting midges (Diptera: Ceratopogonidae) and human health. J Med Entom 20: 347364.

12. Hoch AL, Roberts DR, Pinheiro FP, 1986. Breeding sites of Culicoides paraensis and options for control by environmental management. Bull Pan Am Health Organ 20: 284-293.

13. Hoch AL, Roberts DR, Pinheiro FP, 1990. Host-seeking behavior and seasonal abundance of Culicoides paraensis (Diptera: Ceratopogonidae) in Brazil. J Am Mosq Cont Assoc 6: 110114.

14. Boorman J, 1993. Biting midges (Ceratopogonidae). Lane RP, Crosskey RW, eds. Medical Insects and Arachnids. London: Chapman and Hall, 289-309. 